\title{
Development of an Olive Phenological Model in Relation to Air Temperature
}

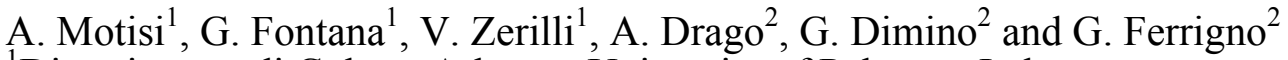 \\ ${ }^{1}$ Dipartimento di Colture Arboree, University of Palermo, Italy \\ ${ }^{2}$ Servizio Informativo Agrometerologico Siciliano, Assessorato Agricoltura e Foreste, \\ Palermo, Italy
}

Keywords: phenological model, heat accumulation, temperature threshold

\begin{abstract}
The effect of air temperature on olive phenological development has not been extensively studied. Indirectly related data are available, mostly from air pollen concentration measurements rather than direct observation of phenological stages. Data on phenological stages of olive collected in Sicily, by the Sicilian Agrometeorological Service (SIAS), in 10 locations characterized by different climatic conditions were used to develop and calibrate a phenological model for the most important developmental stages in olive. Phenological stages under study were: bud break, inflorescence emission, and full bloom $A$ base-temperature linear model was developed by choosing a temperature threshold using as optimization criteria the Mean Bias Error (MBE) and the $R^{2}$ of the relationship between observed vs. predicted phenological stage dates. A model with base temperature of $12^{\circ} \mathrm{C}$ was found to be the best predictor for all initial phenological stages. A more detailed analysis within each single phase showed a decreasing performance compared to predictions performed on the whole period (January $1^{\text {st }}$ to full bloom). Highest displacements of model predictions from observed values occurred starting from bloom, whereas bud-break predictions had the best fit, with lowest residuals. This difference in the predicting ability of the model in different phenological stages could be ascribed to the stronger limitations by low temperatures that can occur early in the season, as for bud-break stage.
\end{abstract}

\section{INTRODUCTION}

Phenology is the study of the timing of periodic biological events, and their relationship with the environment, especially climate (Lieth, 1974). In Mediterranean areas, olive phenological development is related to meteorological conditions and geographical characteristics.

The effect of air temperature on phenological development of olive has not been extensively studied. Few studies, over a sufficiently long-term time-scale and large territorial span of olive phenological series, are available on the effects of temperature on vegetative and reproductive development during the vegetative season and, among these, only a small number are based on direct observation of phenological stages. More consistent data come from air pollen concentration measurements, as a result of several studies performed in several Countries over a long time-span (Galan et al., 2001; GarciaMozo et al., 2002; Ribeiro et al., 2006). A good phenological model is important to implement agrometeorological applications to give different possible decision support systems: disease and pest management, irrigation, allergenic problems, harvest date forecasting. Agroclimatological applications are also of interest, mostly to define relationships between topoclimatological and cultivar-specific characteristics, such as ripening date and length of ripening period and quality of olive products. Thus, it was considered useful to conduct investigations on temperature thresholds to define a performing phenological model by using a "rich" phenological data set.

The Sicilian Agrometeorological Information Service (SIAS), supports the olive industry, aiming to characterise oil quality, on the basis of local cultivars and production systems "Protected Denominations of Origin", by developing and applying a functional phenological model, to support olive farmers operational decisions, and has established a 
long-term, extensive phenological monitoring activity, that is implemented through a network of observational sites, ranging over a wide set of environmental conditions and cultivars. The present study uses the phenological dataset collected through this network, to develop a phenoclimatic model based on air temperature records.

\section{MATERIALS AND METHODS}

\section{Phenological Data}

Main olive phenological data used in the present study was an extensive database composed by phenological records collected at weekly frequency in Sicily, by the Sicilian regional agrometeorological service (SIAS), for 6 cultivars (Ogliarola Messinese, Nocellara del Belice, Santagatese Cerasuola, Biancolilla, Tonda Iblea, Moresca) from 1997 until 2004, in more than 50 sites. Location of observational sites was chosen to cover as much of the range of environmental and cultural conditions which interests olive growing in Sicily, including, as geographic sources of variability, both altitude above sealevel of orchard's location and its distance from Island's coastline. In this phenological data set, phenological stages considered were: bud break, inflorescence emission, full bloom, fruit-set, pit-hardening and turning-dark coloured ("invaiatura"), by using an operational, simplified phenological scale (Drago and Lombardo, 1999; Barbieri et al., 1989).

This study was limited to the analysis to 3 olive cvs., Ogliarola Messinese, Nocellara del Belice and Santagatese, in 10 sites. The Ogliarola M. phenological data were recorded in 4 sites: Collesano (PA), Spadafora (ME), Rometta (ME) and San Pier Niceto (ME); the Nocellara B. phenological data were recorded in 3 sites: Trapani, Mezzoiuso (PA) and Cefalà Diana (PA); the Santagatese phenological data were recorded in 3 sites: Pettineo (ME), Tusa (ME) and Mistretta (ME). Main geographical characteristics of the sites and the years studied are shown in Table 1.

\section{Model Development}

The problems involved in estimating the best threshold temperature for plant development in a range of climates have been discussed for several years both in agronomy and botany and more recently in phenology and aerobiology (Garcia-Mozo et al., 2002). Threshold temperature actually vary according to several factors in both, plant and the environment (Snyder et al., 1999; Chuine and Rosseau, 1999; Wielgolasky, 1999).

To establish the optimum base temperature for olive in the "initial stages" (winter, spring) we first calculated the linear relationship between the development rate (1/phase duration in days) (Arnold, 1959) and the mean temperature along bud break, inflorescence emission and full bloom phases and then calculated the heat accumulation over a wide range of possible thresholds $\left(0-16^{\circ} \mathrm{C}\right)$. Therefore, phenological phases and stages studied were: bud break, inflorescence emission, full bloom. We considered a tree to be in each phenological stage when at least $50 \%$ was in that stage.

In the present study heat accumulation, Growing Degree Days (GDD) method was calculated from 1 January to the date in which each phenological stage was attained. Base-temperature $(\mathrm{Tb})$ values tested were in the range $0-16^{\circ} \mathrm{C}$. We did not include chilling calculations in the model because this has not been conclusively demonstrated.

The general mean GDD accumulation was used as a reference thermal time requirement for estimating date of each phenological event. The most accurate temperature threshold was chosen, taking into account both the best linear regression $\left(\mathrm{R}^{2}\right)$ between predicted and observed phenological date and lowest mean bias error (Willmott, 1982) $\left(\mathrm{MBE}=\sum\right.$ (predicted date - observed date $) /$ number of cases $)$.

To help in solving ambiguities about the choice of temperature threshold in presence of different "local estimates", a mean daily temperature frequency analysis over the entire observation period was performed, giving preference to the "local estimated" $\mathrm{Tb}$ closest to the highest-frequency temperature values. This helped to avoid over- 
optimization which has the effect of selecting base-temperatures very distant from air temperature values that generally occur in the environments included in the study.

Weather data from SIAS meteorological data sets were used to calculate heat accumulation for each period, using maximum, mean and minimum daily temperature data recorded in weather stations near phenological stations. For some phenological stations, meteorological series were estimated by a topoclimatic interpolation approach, using the closest weather station data.

\section{RESULTS}

Olive phenology in both datasets analysed for this study showed a high variability in relation to both geographical location and interannual meteorological variability. In cv. Nocellara del Belice data collected in 2006 on the BBCH scale the highest variation among sites was observed for the earliest phenological stages: differences between the earliest and lates dates of bud-break and bloom, respectively, were 20 and 25 days. These latter stages correspond to the periods (winter and early spring) in which temperature deficit limitations to phenological development are likely to occur in the Mediterranean (Fig. 1). The differences in phenology observed in the earliest stages, however, cancelled out in the later stages, occurring during summer, when temperatures are generally at optimum or above-optimum. No differences among the four locations were observed for ripening date, which in the olive occurs at the end of the season.

On the main extensive dataset, earliest bud break stage date was recorded on 6 February while the latest one on 6 May; the inflorescence emission stage dates ranged from 17 March to 20 May, while full bloom stage dates ranged from 18 April to 5 June. We also analysed date variability for each phenological stage in relation to altitude. For this purpose we divided all studied sites in two altitude range groups: $0-300 \mathrm{~m}$ and 300 $610 \mathrm{~m}$.

The phenological stage dates variability related to the different two altitude ranges is shown in Table 2. The highest mean difference in the two altitude range groups was observed for bud break stage. For this phenological phase, in fact, is very important the thermal limitation for plant development.

To estimate dependency of phenological stages on temperature, data for all cases were plotted as the inverse of the duration (in days) for bud break versus the mean temperature values for the whole period. The inverse of duration (1/days) represents the development rate. This analysis showed that thermal time procedure is appropriate for our dataset. A linear increase in thermal development rate with mean temperature was found, considering whole data set (cultivars, locations, years).

Since the main focus of the present study were the first developmental stages (from bud-break to full-bloom) of the annual developmental cycle, a simple model linearly relating olive phenology to air temperature was chosen. Therefore a thermal accumulation model, by GDD method, was developed and tested for forecasting bud break, inflorescence emission and full bloom stage dates.

The most accurate temperature threshold was chosen taking into account both the best linear regression $\left(\mathrm{R}^{2}\right)$ between predicted and observed phenological date and lowest mean bias error (MBE), considering the following periods: 1 January - bud break stage, 1 January - inflorescence emission stage and 1 January - full bloom stage.

Results of optimization process showed that, in the range of base-temperature $(\mathrm{Tb})$ tested, 0 to $16^{\circ} \mathrm{C}$, the highest $\mathrm{Tb}$ considered gave the lowest coefficients of determination and the highest mean bias error values. Constant improvements in objective functions (increase in $\mathrm{R}^{2}$ and decrease in MBE) were observed for decreasing values of $\mathrm{Tb}$ up to a value (between $11^{\circ} \mathrm{C}$ and $12^{\circ} \mathrm{C}$ ) below which the rate of improvement did not further change significantly. Due to this change in the trend, the lowest range of thresholdtemperature considered $\left(\mathrm{Tb}>0\right.$ through $\left.\mathrm{Tb}<12^{\circ} \mathrm{C}\right)$ did not show significant differences in $\mathrm{R}^{2}$ and MBE, showing good-performing values in both $\mathrm{R}^{2}$ and MBE.

This result indicates an ambiguity of optimization procedures utilized for basetemperature determination which could have affected other studies in olive and could be 
the reason of the contrasting values, from less than $2^{\circ} \mathrm{C}$ up to $14^{\circ} \mathrm{C}$, of base temperature reported in literature. To solve this ambiguity, in the present study it was considered reasonable to take the point of significant change in both $\mathrm{R}^{2}$ and MBE values as the best temperature threshold $(\mathrm{Tb})$ of the model (Fig. 2). This point in the present dataset occurred between 11 and $12^{\circ} \mathrm{C}$.

Furthermore to support the criterion used in solving ambiguities about the choice of temperature threshold in presence of different "local" candidate solutions, a mean daily temperature frequency analysis all over the observation period was performed. This analysis showed that the choice of lowest temperature thresholds $\left(0-9^{\circ} \mathrm{C}\right)$ would have provided $\mathrm{Tb}$ values not significantly different, in model behaviour, for this mean temperatures distribution data set. This is because of the very low frequencies of air temperature values observed in the range $0-9^{\circ} \mathrm{C}$ (Fig. 3) that do not weigh on model estimates.

On the basis of the concordance of both discrimination criteria, change of rate of improvement of objective functions and frequency of occurrence in meteorological data, applied to the results of optimization process, a $\mathrm{Tb}$ value of $12^{\circ} \mathrm{C}$ was chosen as the best temperature threshold for heat accumulation in the initial phenological phases of olive. Similar results were observed in other studies about heat accumulation for olive in Mediterranean areas (Alcalà and Barranco, 1992; Galàn et al., 2001).

Regression analysis of observed phenological stage dates versus simulated phenological stage dates from 1 January to bud break, from 1 January to inflorescence emission and from 1 January to full boom, showed a strong linear relationship (Fig. 4a, b, c) with slope close to 1, denoting a high goodness-of-fit and low or null bias on model's predictions.

\section{DISCUSSION}

Results of this work give us valuable information from agronomic and allergenic points of view. Air temperature directly affects olive phenological cycle and therefore has immediate consequences on crop production. In the dataset used in the present study, bloom date showed greatest change as a function of temperature in relation both to yearto-year variation and to geo-topographical factors.

A detailed analysis of model predictions within each single phase showed a decreasing performance compared to predictions performed over the whole period (January $1^{\text {st }}$ to full bloom). Highest displacements of model predictions from observed values occurred for bloom, whereas bud-break predictions had the lowest residuals. This difference in the predicting ability of the model in different phenological stages could be ascribed to the stronger limitations of low temperatures that can occur early in the season for bud-break stage. For the bloom stage, on the other hand, control factors other than temperature, which have not been considered in this study, could have played an important role in determining bloom date.

\section{ACKNOWLEDGEMENTS}

We wish to thank all Sicilian Extension Service technicians and offices who collected phenological data: SOAT 1, 11, 29, 37, 54, 59, 60, 66, 67, 78, 83, 85, 87.

\section{Literature Cited}

Alcalà, A.R. and Barranco, D. 1992. Prediction of flowering time in olive for the Cordoba Olive Collection. HortScience 27:1205-1207.

Arnold, C.Y. 1959. The development and significance of the base temperature in a linear heat unit system. Proc. Am. Soc. Hort. Sci. 74:430-445.

Barbieri, R., Botarelli, L., Salsi, A. and Zinoni, F. 1989. Guida alle rivelazioni agrofenologiche e alla compilazione delle schede di rilevamento per le colture erbacee ed arboree. ERSA-Servizio Meteorologico regionale, Bologna. 
Chuin, P.C. and Rousseau, D.D. 1999. Selecting models to predict the timing of flowering of temperature trees: implications for tree phenology modelling. Plant, Cell and Environment 22:1-13.

Drago, A. and Lombardo, M.. 1999. Manuale per le rilevazioni fenologiche sull'olivo. Regione Siciliana, Assessorato Agricoltura e Foreste, Unità di Agrometeorologia, Palermo.

Galàn, C., Garcia-Mozo, H. and Alcazar, P. 2001. The Role of temperature in the onset of the Olea Europea L. pollen season in southwestern Spain. Intl. J. Biometeorol. 45:812.

Garcia-Mozo, H., Galan, C., Aira, M.J., Belmonte, J., Diaz de la Guardia, C., Fernandez, D., Gutierrez, A.M., Rodriguez, F.J., Trigo, M.M. and Dominguez-Vilches, E. 2002 Modelling start of oak pollen season in different cliamtic zones in Spain. Agriculture and Forest Meteorology 110:274-257.

Lieth, H. 1974. Phenology and Seasonality Modelling. Springer Verlag, New York.

Ribeiro, H., Cunha, M. and Abreu, I. 2006. Comparison of classical models for evaluating the heat requirement requirements of olive (Olea europaea L.) in Portugal. J. of Integrative Plant Biology 48(6):664-671.

Snyder, RL., Spano, D. Cesaraccio, C. and Duce, P. 1999. Determining degree-day thresholds from field observations. Intl. J. Biometeorol. 42:124-133.

Wielgolasky, F.E. 1999. Starting dates basic temperatures in phenological observations of plants. Intl. J. Biometeorol. 42:158-168.

\section{$\underline{\text { Tables }}$}

Table 1. Main geographical characteristics of sites of olive phenological observations.

\begin{tabular}{lcclc}
\hline Municipality & Province & Altitude $(\mathrm{m})$ & Olive Cultivar & Years \\
\hline \hline Pettineo & Messina & 250 & Santagatese & $1997-2004$ \\
Tusa & Messina & 380 & Santagatese & $1997-2003$ \\
Mistretta & Messina & 460 & Santagatese & $1998-2003$ \\
Trapani & Trapani & 281 & Nocellara del Belice & $1997-1998$ \\
Trapani & Trapani & 48 & Nocellara del Belice & $1997-1998$ \\
Mezzoiuso & Palermo & 320 & Nocellara del Belice & $1997-2000$ \\
Cefala Diana & Palermo & 610 & Nocellara del Belice & $1997-2000$ \\
Collesano & Palermo & 300 & Ogliarola Messinese & $1997-1998$ \\
Spadafora & Messina & 190 & Ogliarola Messinese & $1997-2000$ \\
Rometta & Messina & 310 & Ogliarola Messinese & $1997-2000$ \\
San Pier Niceto & Messina & 105 & Ogliarola Messinese & $1997-2000$ \\
\hline
\end{tabular}

Table 2. Variability of phenological stages at two altitudes.

\begin{tabular}{lccc}
\hline $\begin{array}{l}\text { Altitude } \\
\text { m a.s.1. }\end{array}$ & \multicolumn{3}{c}{$\begin{array}{c}\text { phenological stage } \\
\text { (day of year) }\end{array}$} \\
\cline { 2 - 4 } & Bud-break & Inflorescence emission & Full bloom \\
\hline $0-300$ & $48-97$ & $76-140$ & $108-154$ \\
$300-610$ & $53-126$ & $97-137$ & $122-156$ \\
\hline
\end{tabular}




\section{Figures}

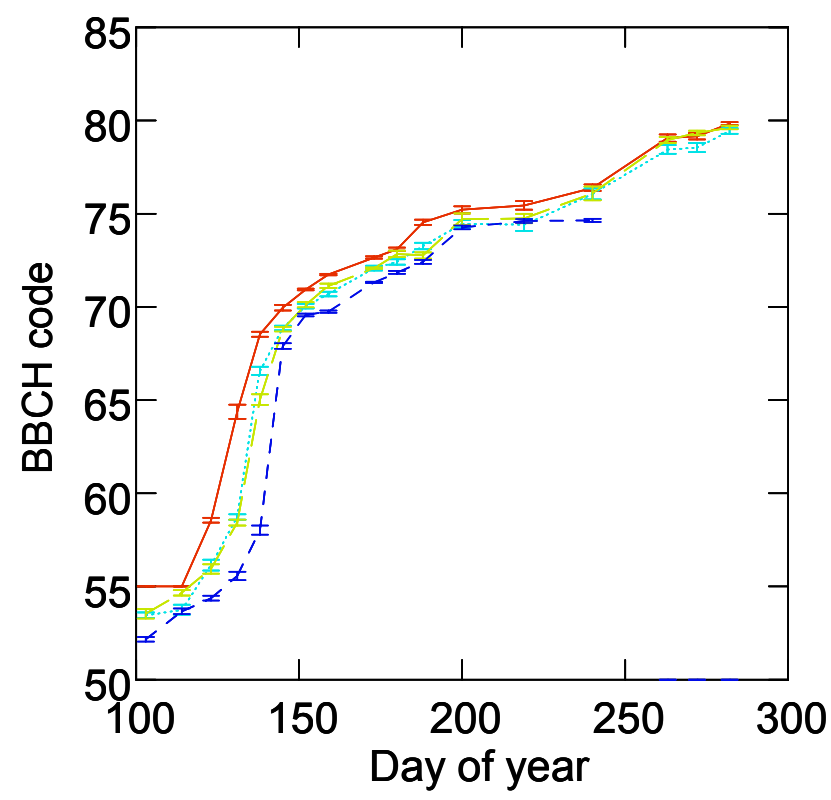

Elevation (m a.s.I.)

50

100

200

300

Fig. 1. Time course of olive phenology (BBCH scale) in cv. Nocellara del Belice grown at different locations.

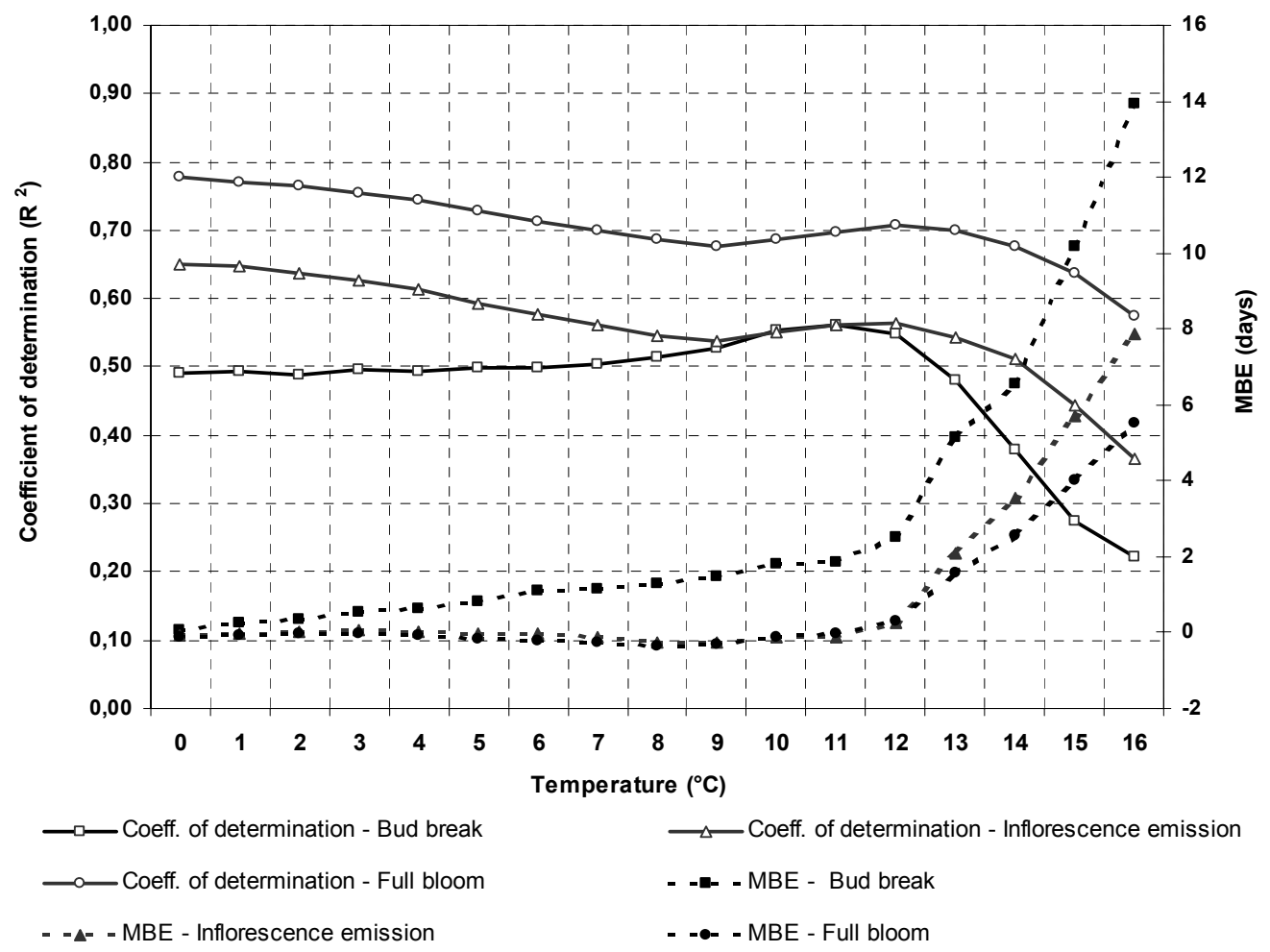

Fig. 2. Linear regression $\left(\mathrm{R}^{2}\right)$ between predicted and observed phenological date and lowest mean bias error (MBE), considering the following periods: 1 Jan. - bud break stage, 1 Jan. - inflorescence emission stage and 1 Jan. - full bloom stage. 


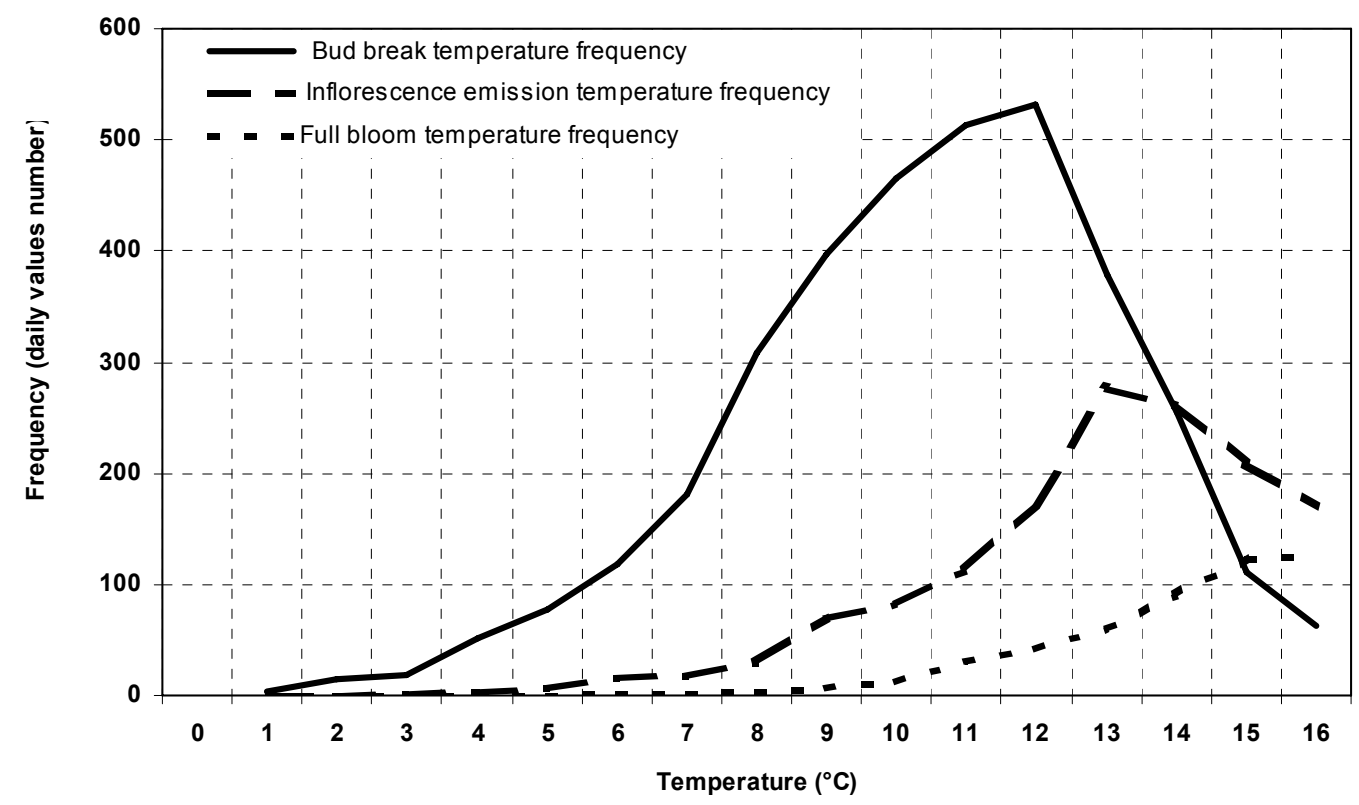

Fig. 3. Mean temperatures frequency all over the observation period: 1 Jan. - bud break stage, 1 Jan. - inflorescence emission stage and 1 Jan. - full bloom stage. 

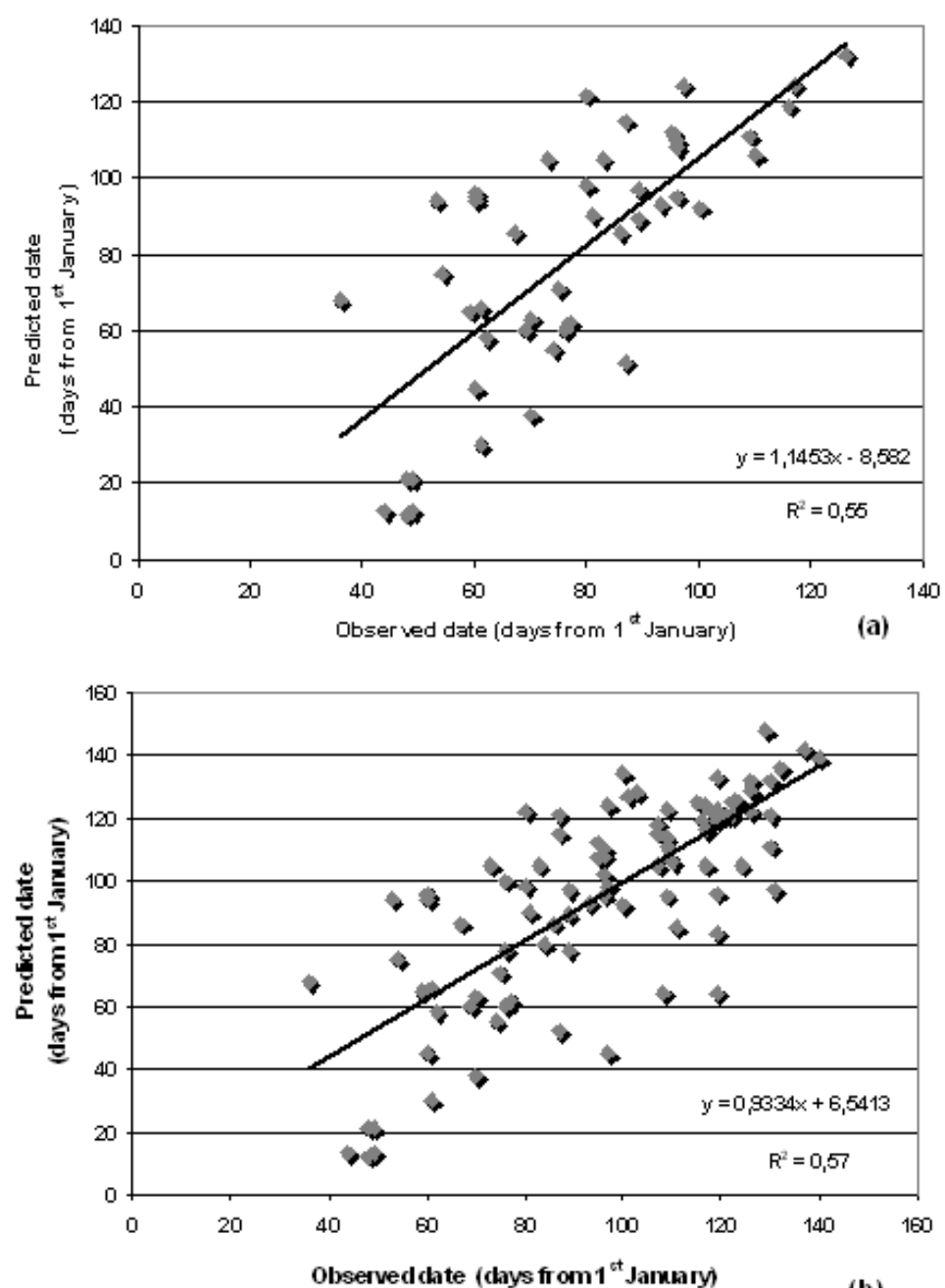

(b)

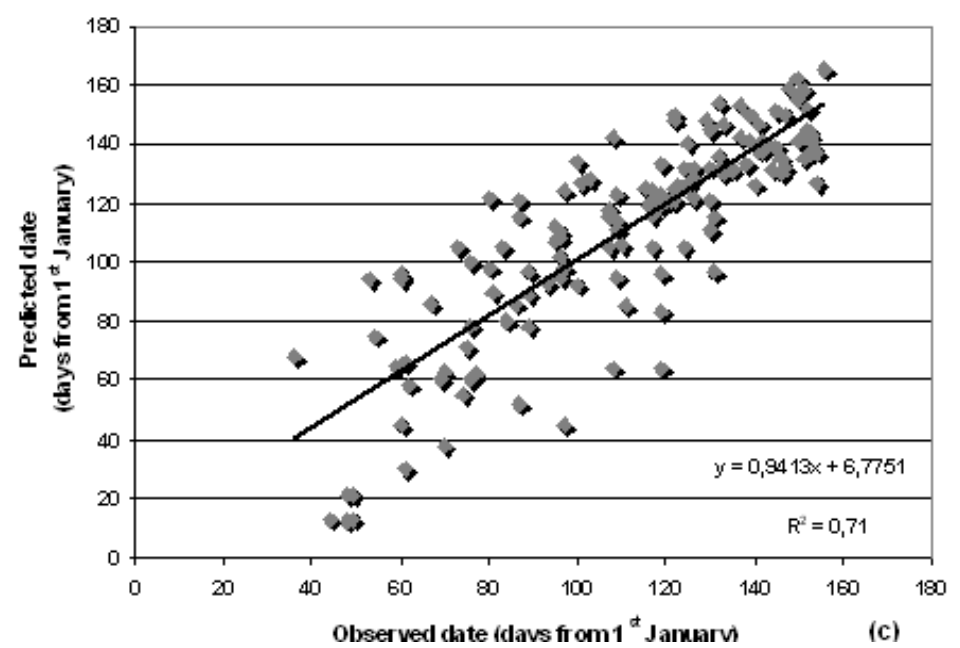

Fig. 4. Regression analysis of observed phenological stage dates versus predicted phenological stage dates from 1 January to bud break (a), from 1 January to inflorescence emission (b) and from 1 January to full boom (c). 